\title{
Euphorbiae humifusae induces apoptosis in Hep3B hepatocarcinoma cells via simultaneous activation of the death receptor-mediated and mitochondrial pathways
}

\author{
SANG HO SEO ${ }^{1}$, DONG YEOK SHIN ${ }^{2}$, SU HYUN HONG $^{2}$, SANG EUN PARK ${ }^{1}$, \\ YUNG HYUN $\mathrm{CHOI}^{2,3}$ and SANG HOON HONG ${ }^{1}$ \\ Departments of ${ }^{1}$ Internal Medicine and ${ }^{2}$ Biochemistry, Dongeui University College of Oriental Medicine; \\ ${ }^{3}$ Department of Biomaterial Control, Dongeui University Graduate School, Busan 614-052, Korea
}

Received August 26, 2008; Accepted December 24, 2008

DOI: 10.3892/or_00000087

\begin{abstract}
In the present study, we investigated the effects of the water extract of Euphorbiae humifusae (WEEH), an oriental medicinal herb, on the growth of Hep3B human hepatocarcinoma cells. We found that WEEH treatment resulted in a significant decrease in the cell viability of Hep3B cells depending on dosage. This decrease was revealed to be apoptosis, evidenced by chromatin condensation, DNA fragmentation and an accumulation of apoptotic fraction. WEEH induced the expression of death receptor-related proteins such as Fas, tumor necrosis factor-related apoptosisinducing ligand, death receptor (DR) 4 and DR5, which further triggered caspase- 8 activation and truncated Bid cleavage. Mitochondrial dysfunction, the catalytic activation of caspase-9, down-regulation of anti-apoptotic Bcl-2 and Bcl-xL expression, and up-regulation of the pro-apoptotic Bax protein were also observed in WEEH-treated cells. In addition, the increase in apoptosis induced by WEEH was correlated with caspase- 3 activation and the concomitant degradation of poly (ADP-ribose) polymerase. However, the cytotoxic effects and apoptotic characteristics induced by WEEH were significantly inhibited by z-DEVD-fmk, a caspase-3 inhibitor. This demonstrates the important role played by caspase- 3 in the process. Collectively, our data indicate that WEEH induces Hep3B cell apoptosis through a signaling cascade of death receptor-mediated extrinsic and mitochondria-mediated intrinsic caspase pathways.
\end{abstract}

Correspondence to: Dr Yung Hyun Choi, Department of Biochemistry, Dongeui University College of Oriental Medicine, Busan 614-052, Korea

E-mail: choiyh@deu.ac.kr

Dr Sang Hoon Hong, Department of Internal Medicine, Dongeui University College of Oriental Medicine, Busan 614-052, Korea E-mail: shhong@deu.ac.kr

Key words: Euphorbiae humifusae, Hep3B, apoptosis

\section{Introduction}

Apoptosis is the active process of programmed cell death that occurs during many important physiological conditions, such as embryonic development and tissue remodeling. However, most cancer cells block apoptosis, which allows them to survive despite undergoing genetic and morphological transformations. Apoptosis is characterized by distinct morphological changes, including plasma membrane blebbing, cell shrinkage, cell surface expression of phosphatidylserine, mitochondrial depolarization, chromatin condensation, and DNA fragmentation. Several genes have been identified as either inducers or repressors of apoptosis (1-3). In general, apoptosis can be initiated by the Fas/tumor necrosis factor (TNF) death receptor (extrinsic) pathway or the mitochondrialdependent (intrinsic) pathway, leading to the activation of caspase and consequent apoptosis in mammalian cells (4-6). Depending on the nature of the substance and the cell type, apoptosis may occur via either pathway. In the former case, plasma membrane death receptors are involved and the apoptosis signal is provided by the interaction between the ligand and death receptor. However, changes in mitochondrial integrity by a broad range of physical and chemical stimuli can trigger the intrinsic pathway of apoptosis $(5,7,8)$. Besides morphological and biological changes, several other biomarkers and events can be used for the precise determination of the type of apoptosis. Accumulating data show that many chemopreventive and/or chemotherapeutic agents can cause cancer cell death via the induction of apoptosis, which is the preferred method for managing cancer. Therefore, the induction of apoptotic cell death is an important mechanism by which the anti-cancer properties of many drugs function.

One of the current attractive strategies considered in cancer chemoprevention and chemotherapy is dietary or pharmaceutical manipulation, used to induce the cell death of malignant cells through apoptosis. Recently, there has been a great deal of evidence that herbal medicine causes antitumoral activity by inducing apoptosis in human cancer cells (9-12). Used as a type of folk medicine, Euphorbiae humifusae is an important oriental herb frequently prescribed in Korea, P.R. China and Japan, along with other herbs to treat asthma, edema, constipation and abdominal masses $(13,14)$. Flavonoids 
including esculetin and quercetin are significant components of this plant. Previous researchers have suggested that these have various biological effects, including anti-tumor and antiinflammatory activities $(15,16)$. However, the underlying therapeutic mechanism of E. humifusae is unclear. Recently, we reported that the water extract of E.humifusae (WECM) inhibits cyclooxygenase-2 expression and prostaglandin E2 production through the inhibition of nuclear factor- $\mathrm{kB}$ activation $(17,18)$, and induces apoptosis in AGS human gastric cancer cells (19). Although the effectiveness of E. humifusae in the treatment of human liver cancer has been widely demonstrated, its effect on cancer cell proliferation and apoptosis has yet to be sufficiently explained. As part of our search for novel biologically active substrates for the prevention and treatment of liver cancer using traditional medicinal herb resources, we evaluated the apoptotic potential of WEEH in Hep3B human hepatocarcinoma cells. We also investigated the mechanism of WEEH-induced apoptosis by analyzing apoptosis signaling.

\section{Materials and methods}

Cell culture, Euphorbiae humifusae treatment and cell viability assay. Human hepatocarcinoma Hep3B cells were purchased from the American Type Culture Collection (Rockville, MD, USA). Hep3B cells were cultured in Dulbecco's modified Eagle's medium (DMEM) containing $100 \mathrm{U} / \mathrm{ml}$ penicillin/ streptomycin and supplemented with $10 \%$ heat-inactivated fetal bovine serum (FBS, Gibco BRL, Gaithersburg, MD, USA) at $37^{\circ} \mathrm{C}$ and $5 \% \mathrm{CO}_{2}$. E. humifusae (WEEH) was supplied by Dongeui University Oriental Hospital (Busan, Korea). Water extract from the leaves of E. humifusae was prepared as previously described (19). In brief, distilled water at $95^{\circ} \mathrm{C}$ was added to dried leaves, and the temperature was maintained for $10 \mathrm{~h}$. The mixture was allowed to cool to room temperature, then was filtered and lyophilized. The extracts were dissolved directly in distilled water as a stock solution at a concentration of $10 \mathrm{mg} / \mathrm{ml}$, and stored in aliquots at $-20^{\circ} \mathrm{C}$. Cell viability measurements were determined using the 3 (4,5-dimethyl-thiazol-2-yl)-2,5-diphenyl-tetrazolium bromide assay (MTT, Sigma Chemical Co., St. Louis, MO, USA), which is based on the conversion of MTT to MTT-formazan by the mitochondrial enzyme (20).

Nuclear staining with DAPI. The untreated control and WEEH-treated Hep3B cells were harvested and washed with phosphate-buffered saline (PBS). Cells were fixed with 3.7\% paraformaldehyde (Sigma) in PBS for $10 \mathrm{~min}$ at room temperature. The fixed cells were collected using cytospin, washed with PBS and stained with 4,6-diamidino-2phenylindole (DAPI, Sigma) solution for $10 \mathrm{~min}$ at room temperature. The cells were then washed twice more with PBS and analyzed via a fluorescence microscope (Carl Zeiss, Germany).

Agarose gel electrophoresis for DNA fragmentation assay. Following WEEH treatment, cells were lysed in a buffer containing $10 \mathrm{mM}$ Tris- $\mathrm{HCl}$ (pH 7.4), $150 \mathrm{mM} \mathrm{NaCl}, 5 \mathrm{mM}$ ethylenediaminetetra acetic acid (EDTA) and $0.5 \%$ Triton $\mathrm{X}-100$ for $30 \mathrm{~min}$ on ice. The lysates were vortexed and cleared by centrifugation at $10,000 \mathrm{x} \mathrm{g}$ for $20 \mathrm{~min}$. DNA in the supernatant was extracted using an equal volume of 25:24:1 (v/v/v) neutral phenol:chloroform:isoamyl alcohol (Sigma), and analyzed electrophoretically on $1.0 \%$ agarose gels containing $0.1 \mu \mathrm{g} / \mathrm{ml}$ ethidium bromide (EtBr, Sigma).

Measurement of apoptosis by annexin-V fluorescein isothiocyanate and propidium iodide double staining. The magnitude of the apoptosis elicited by WEEH treatment was determined using an Annexin-V fluorescein isothiocyanate (FITC) apoptosis detection kit (BD Pharmingen, San Diego, CA, USA). In brief, cells were washed with PBS and resuspended in annexin- $\mathrm{V}$ binding buffer containing $10 \mathrm{mM}$ HEPES/ $\mathrm{NaOH}$ (pH 7.4), $140 \mathrm{mM} \mathrm{NaCl}$ and $2.5 \mathrm{mM} \mathrm{CaCl}_{2}$, according to the manufacturer's protocol. Cell aliquots were incubated with annexin-V FITC, mixed and incubated for $15 \mathrm{~min}$ at room temperature in the dark. Propidium iodide (PI) at a concentration of $5 \mu \mathrm{g} / \mathrm{ml}$ was added to identify the necrotic cells. The apoptotic cells were measured by fluorescenceactivated cell sorter analysis in a flow cytometer (Becton Dickinson, San Jose, CA, USA) (21).

Protein extraction, gel electrophoresis and Western blot analysis. Total cell lysates were lysed in an extraction buffer [25 mM Tris- $\mathrm{Cl}$ (pH 7.5), $250 \mathrm{mM} \mathrm{NaCl}, 5 \mathrm{mM}$ EDTA, $1 \%$ nonidet P-40, $0.1 \mathrm{mM}$ sodium orthovanadate, $2 \mu \mathrm{g} / \mathrm{ml}$ leupeptin and $100 \mu \mathrm{g} / \mathrm{ml}$ phenylmethylsulfonyl flouride]. Protein concentration was determined with a Bio-Rad protein assay kit (Bio-Rad, Hercules, CA, USA). For Western blot analysis, proteins $(30 \mu \mathrm{g})$ were separated by $8-13 \%$ sodium dodecyl sulfate (SDS)-polyacrylamide gel electrophoresis and then electrotransferred to a nitrocellulose membrane (Schleicher \& Schuell, Keene, NH, USA). The membranes were blocked with 5\% skim milk for $1 \mathrm{~h}$ and then subjected to immunoblotting with the appropriate antibodies. Proteins were visualized by the enhanced chemiluminescence (ECL) method according to the recommended procedure (Amersham Co., Arlington Heights, IL, USA) (22). Primary antibodies were purchased from Santa Cruz Biotechnology Inc. (Santa Cruz, CA, USA) and Calbiochem (Cambridge, MA, USA). Peroxidase-labeled donkey anti-rabbit immunoglobulin and peroxidase-labeled sheep anti-mouse immunoglobulin were purchased from Amersham.

Measurement of loss of mitochondrial membrane potential $\left(M M P, \Delta \Psi_{m}\right)$. To measure MMP, a dual-emission potentialsensitive probe, 5,5 V, 6,6 V-tetrachloro-1,1 V,3,3 V-tetraethylimidacarbocyanine iodide (JC-1, Sigma), was used. After WEEH treatment, cells were scraped from the bottom of the wells and aliquots of $5 \times 10^{5}$ cells were placed into FACS tubes. The cells were then stained with $2 \mathrm{mg} / 1 \mathrm{JC}-1$ at $37^{\circ} \mathrm{C}$ for $20 \mathrm{~min}$ and analyzed using a flow cytometer (Becton Dickinson).

Caspase activity assay. The activities of caspases-3, -8 and -9 were determined by colorimetric assay kits from R\&D Systems (Minneapolis, MN, USA) following the manufacturer's protocol. The kits used in the present study utilize synthetic tetrapeptides [Asp-Glu-Val-Asp (DEAD) for caspase-3, Ile-Glu-Thr-Asp (IETD) for caspase-8 and Leu-Glu-His- 
A

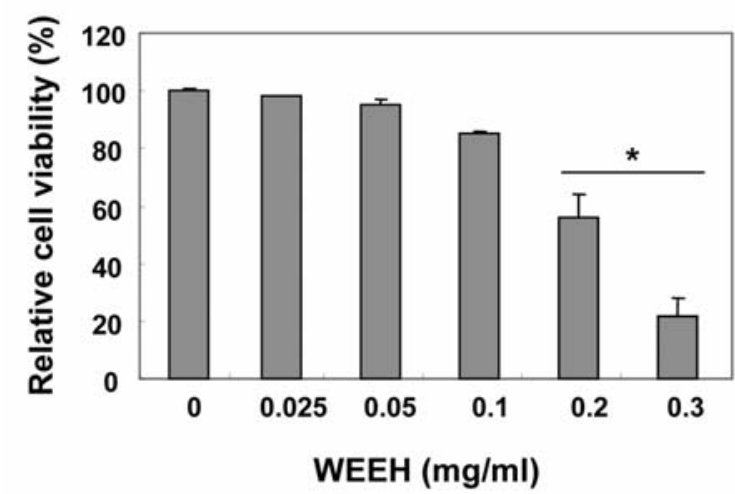

C
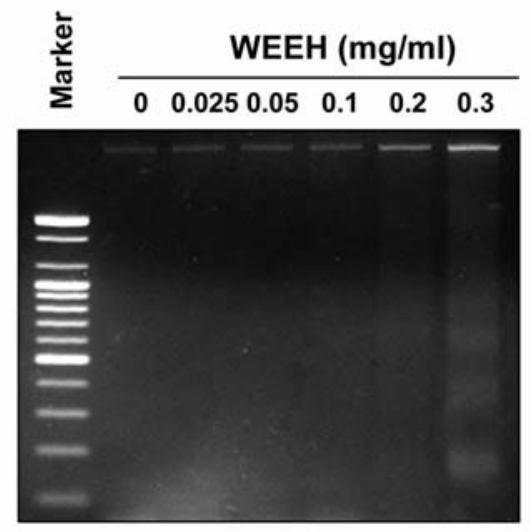

B

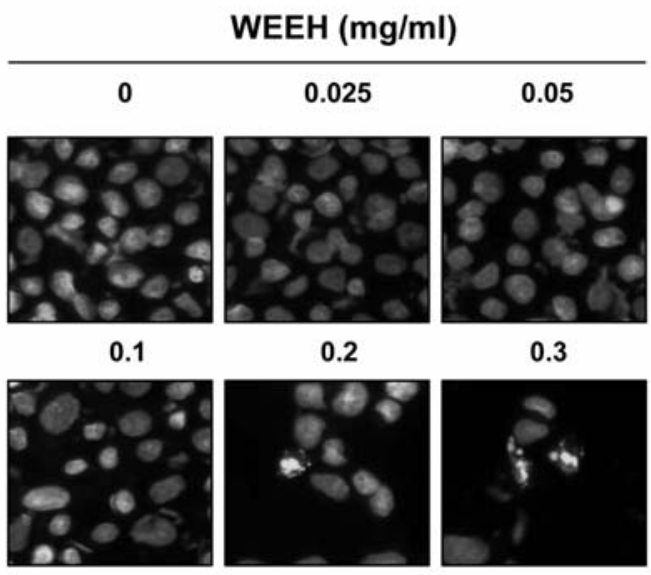

D

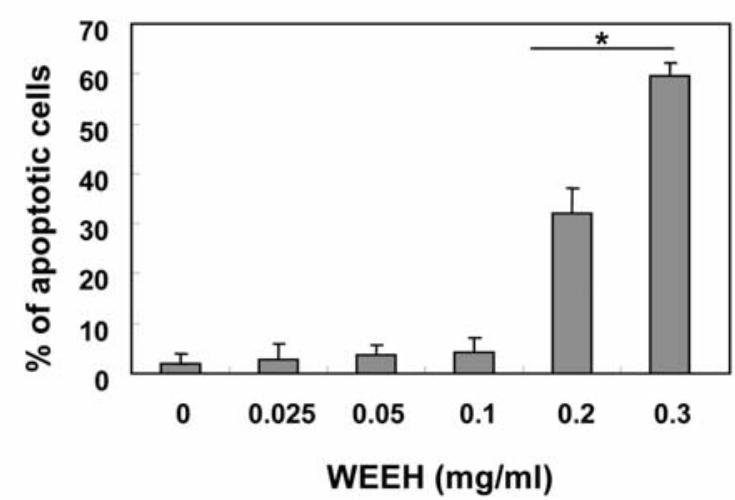

Figure 1. Induction of apoptosis by the water extract of E. humifusae (WEEH) in Hep3B human hepatocarcinoma cells. Hep3B cells were seeded at an initial density of $2.5 \times 10^{5}$ cells per 60 -mm plate, incubated for $24 \mathrm{~h}$ and treated with different concentrations of WEEH for $48 \mathrm{~h}$. (A) The cell viability level was measured using MTT assay. Each point represents the mean \pm SD of three independent experiments. The statistical significance of the results was analyzed by Student's t-test ( $\left.{ }^{*} \mathrm{p}<0.01\right)$. (B) After incubation with WEEH for $48 \mathrm{~h}$, the cells were fixed, stained with DAPI, and the nuclear morphology was photographed with a fluorescent light using a blue filter (magnification x400). (C) For DNA fragmentation analysis, genomic DNA was extracted and analyzed on a 1.0\% agarose gel containing EtBr. (D) Cells grown under the same conditions as (A) were collected and stained with FITC-conjugated annexin-V and PI staining for flow cytometry. Apoptosis in cells was determined by counting the $\%$ of annexin $\mathrm{V}(+) / \mathrm{PI}(-)$ cells and the $\%$ of annexin $\mathrm{V}(+) / \mathrm{PI}(+)$ cells. The results are expressed as the mean \pm SD of three independent experiments. The statistical significance of the results was analyzed using the Student's t-test $\left({ }^{*} \mathrm{p}<0.05\right)$.

Asp (LEHD) for caspase-9] labeled with p-nitroaniline (pNA). In brief, WEEH-treated and untreated cells were lysed in the supplied lysis buffer. The supernants were collected and incubated with the supplied reaction buffer containing dithiothreitol and DEVD-, IETD- or LEHD-pNA as substrates at $37^{\circ} \mathrm{C}$. Reactions were measured by changes in absorbance at $405 \mathrm{~nm}$ using the VERSAmax tunable microplate reader.

Statistical analysis. Results are expressed as the mean \pm standard deviation (SD). A statistical evaluation of the data was performed using the Student's t-test. $\mathrm{P}<0.05$ was statistically significant.

\section{Results}

Growth inhibition and induction of apoptosis by Euphorbiae humifusae treatment. WEEH-induced cell cytotoxicity was determined based on the effects of different WEEH concen- trations on Hep3B cell viability. Data showed that treatment with WEEH for $48 \mathrm{~h}$ decreased the viability of Hep3B cells in a concentration-dependent manner (Fig. 1A). Further experiments were conducted to determine whether this inhibitory effect of WEEH on cell viability was the result of apoptotic cell death. Using morphological analysis with DAPI staining, nuclei with chromatin condensation as well as the formation of apoptotic bodies were observed in the cells cultured with WEEH in a concentration-dependent manner (Fig. 1B). Agarose gel electrophoresis indicated that WEEH treatment induced the progressive accumulation of fragmented DNA, which appeared as a typical ladder pattern of DNA fragmentation due to the internucleosomal cleavage associated with apoptosis (Fig. 1C). Thus, flow cytometry with annexin V and PI staining was used to determine the magnitude of apoptosis elicited by WEEH. As shown in Fig. 1D, the annexin V-positive cells increased concentration-dependently in the WEEH-treated Hep3B cells compared with the untreated control cells. For Hep3B cells treated with 0.2 and $0.3 \mathrm{mg} / \mathrm{ml}$ 
A

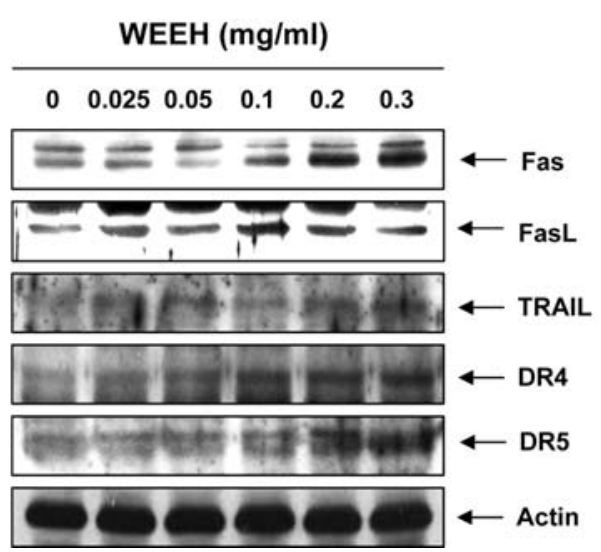

B

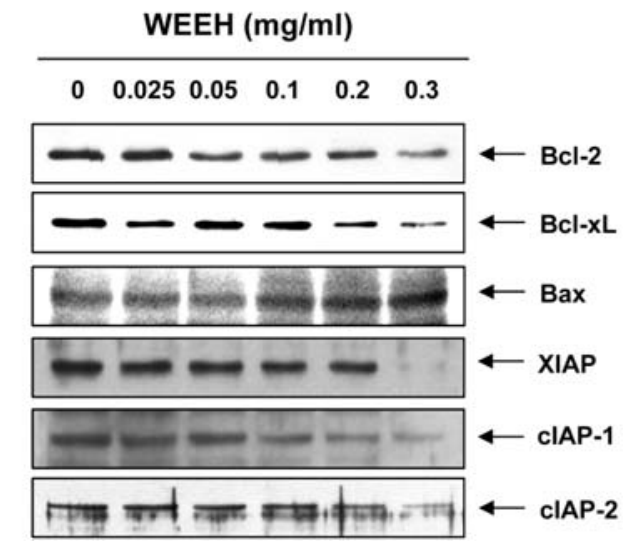

Figure 2. WEEH effects on the levels of apoptosis-related proteins in Hep3B human hepatocarcinoma cells. Cells were treated with the indicated concentrations of WEEH for $48 \mathrm{~h}$. Equal amounts of cell lysates $(30 \mu \mathrm{g})$ were resolved on SDS-polyacrylamide gels and transferred to nitrocellulose membranes. The membranes were probed with the indicated antibodies (anti-Fas, -FasL, -TRAIL, -DR4, -DR5, -Bcl-2, -Bcl-xL, -Bax, -XIAP, -cIAP-1 and -cIAP-2) and proteins were visualized using the ECL detection system. Actin was used as an internal control.

A

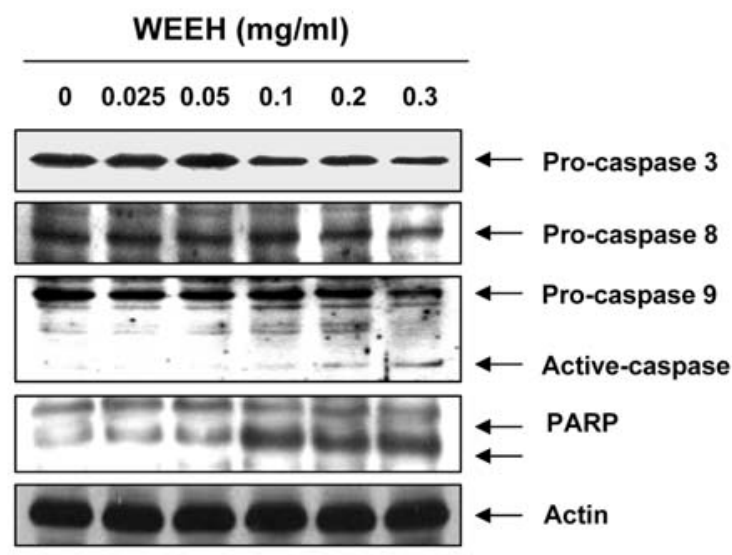

B

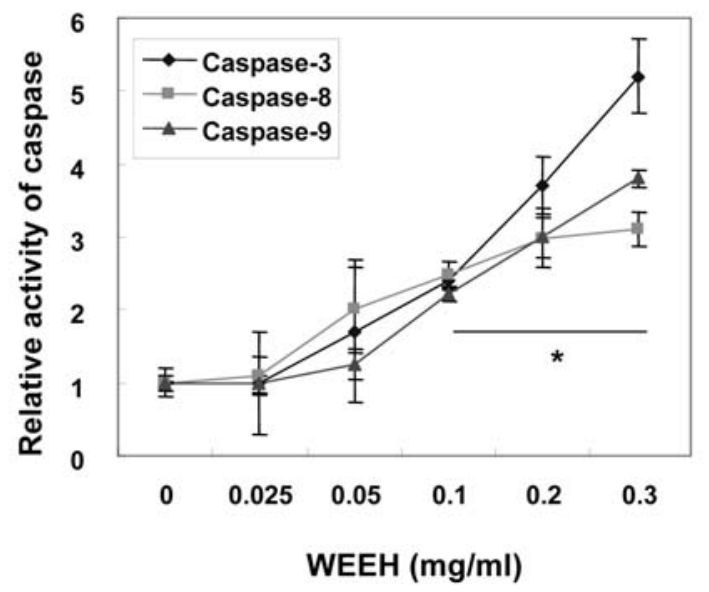

Figure 3. Caspase activation and degradation of the PARP protein by WEEH in Hep3B human hepatocarcinoma cells. (A) After $48 \mathrm{~h}$ of incubation with WEEH, the cells were lysed and cellular proteins were separated by SDSpolyacrylamide gels and transferred onto nitrocellulose membranes. The membranes were probed with anti-caspase- $3,-8,-9$ and anti-PARP antibodies. Proteins were visualized using the ECL detection system. Actin was used as an internal control. (B) The cells grown under the same conditions as (A) were collected and lysed. Aliquots were incubated with DEVD-, IETD- and LEHD-pNA for caspase- $3,-8$ and -9 , individually, at $37^{\circ} \mathrm{C}$ for $1 \mathrm{~h}$. The released fluorescent products were measured. Data represent the mean of three independent experiments. The statistical significance of the results was analyzed by Student's t-test $\left({ }^{*} \mathrm{p}<0.01\right)$
A

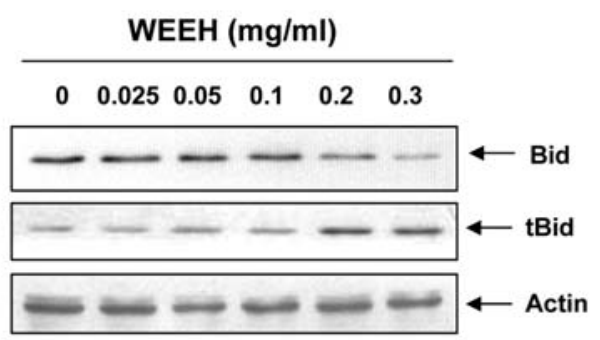

B

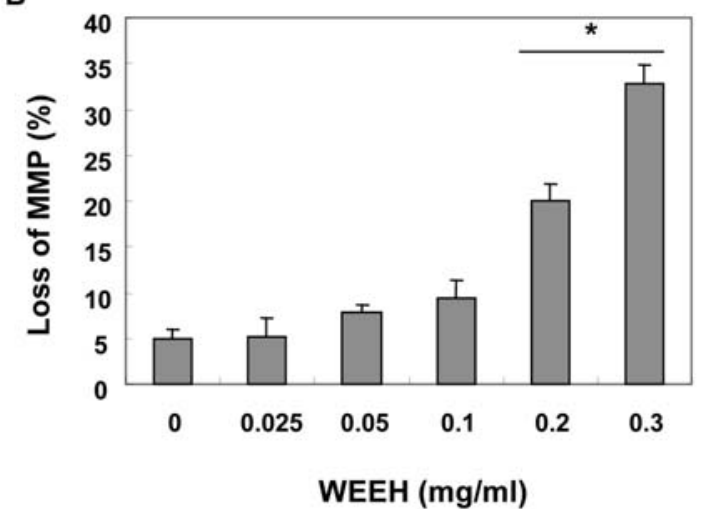

Figure 4. Cleavage of Bid protein and loss of MMP by WEEH in Hep3B human hepatocarcinoma cells. (A) After $48 \mathrm{~h}$ of treatment with WEEH, the cells were lysed and cellular proteins were separated by SDS polyacrylamide gels and transferred onto nitrocellulose membranes. The membranes were probed with anti-Bid antibody. Proteins were visualized using the ECL detection system. Actin was used as a loading control. (B) Cells were treated with the indicated concentrations of WEEH for $48 \mathrm{~h}$, stained with JC-1 and incubated at $37^{\circ} \mathrm{C}$ for 20 min. The mean JC- 1 fluorescence intensity was detected using a flow cytometer. Data represent the mean \pm SD of representative experiments performed at least 3 times. The statistical significance of the results was determined by Student's t-test $\left({ }^{*} \mathrm{p}<0.05\right.$ vs. untreated control).

WEEH for $48 \mathrm{~h}$, apoptosis was $\sim 32$ and 59\%, respectively. These results demonstrate that the cytotoxic effects observed in response to WEEH are associated with the induction of apoptotic cell death in Hep3B cells, and that there is a 
A

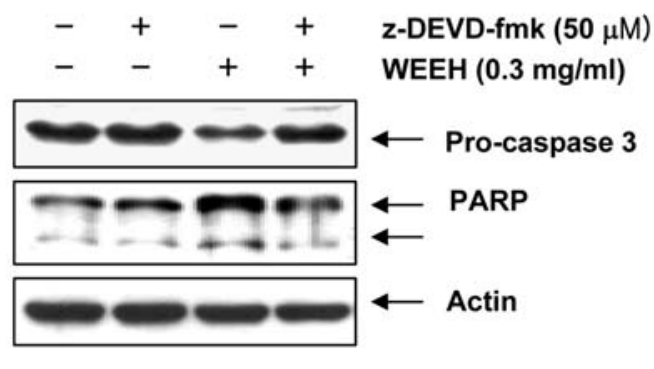

B

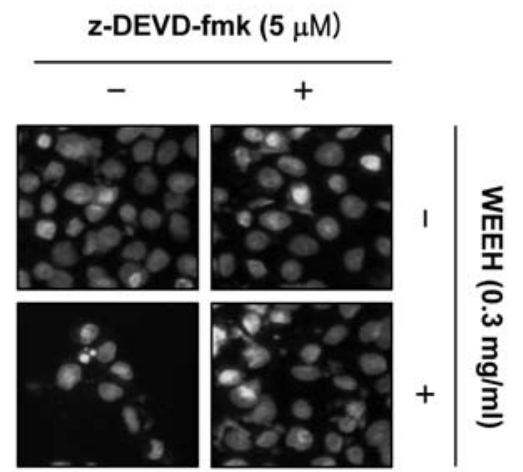

C

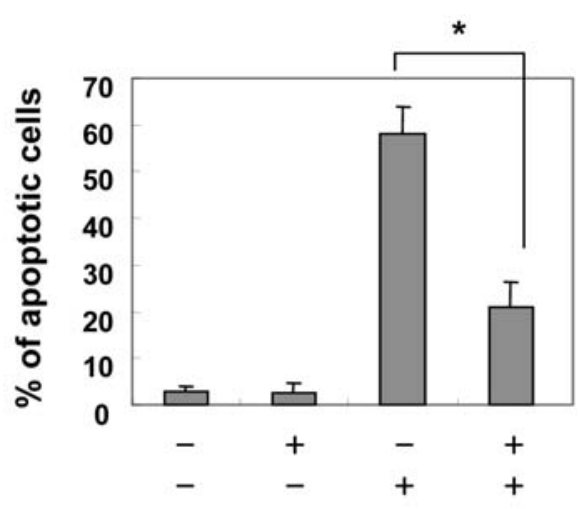

D

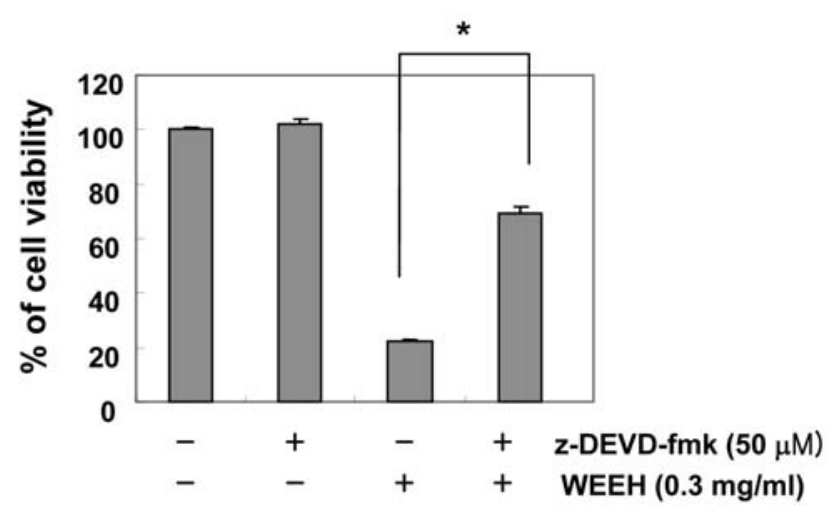

Figure 5. Inhibition of WEEH-induced apoptosis by a caspase-3 inhibitor in Hep3B human hepatocarcinoma cells. (A) Hep3B cells were treated with z-DEVDfmk $(50 \mu \mathrm{M})$ for $1 \mathrm{~h}$ before treatment with $0.3 \mathrm{mg} / \mathrm{ml}$ of WEEH for $48 \mathrm{~h}$. The cells were lysed and cellular proteins were separated by SDS-polyacrylamide gels and transferred onto nitrocellulose membranes. The membranes were probed with anti-caspase-3 and -PARP antibodies. Proteins were visualized using the ECL detection system. Actin was used as an internal control. (B) The cells grown under the same conditions as (A) were stained with DAPI for 10 min and photographed with a fluorescence microscope using a blue filter (magnification, $\mathrm{x} 400$ ). (C and D) Hep3B cells were pretreated for $1 \mathrm{~h}$ with or without $\mathrm{z}-$ DEVD-fmk, and then with WECM for an additional $48 \mathrm{~h}$. The apoptotic cells were determined by counting the $\%$ of annexin V(+)/PI(-) cells and the $\%$ of annexin $\mathrm{V}(+) / \mathrm{PI}(+)$ cells $(\mathrm{C})$. The cell viability level was measured using an MTT assay (D). The results are expressed as the mean \pm SD of three independent experiments. The statistical significance of the results was analyzed by Student's t-test $\left({ }^{*} \mathrm{p}<0.05\right)$.

favourable correlation between the extent of apoptosis and growth inhibition.

Modulation of apoptosis-related proteins by Euphorbiae humifusae in Hep3B cells. To elucidate the apoptotic pathways activated by WEEH, we used Western blot analyses to measure the expression of the death receptors and corresponding proapoptotic ligands, as well as the expression of IAP and Bcl-2 family members. As indicated in Fig. 2, no significant changes in FasL protein levels were noted in Hep3B cells treated with WEEH. However, WEEH increased the expression levels of Fas, tumor necrosis factor-related apoptosis-inducing ligand (TRAIL), death receptor (DR) 4 and DR5 proteins in a concentration-dependent manner. When Hep3B cells were treated with WEEH, a clear decrease in anti-apoptotic Bcl-2 and Bcl-xL protein expression was observed in a concentrationdependent manner. In the case of the pro-apoptotic protein Bax, there was a concentration-dependent up-regulation observed in Hep3B cells treated with WEEH. After WEEH treatment, the levels of IAP family proteins such as XIAP, cIAP-1 and cIAP-2 were down-regulated in Hep3B cells treated with WEEH.
Caspase activation and degradation of poly (ADP-ribose) polymerase protein by Euphorbiae humifusae treatment. Experiments were performed to characterize the role of caspase activation in WEEH-mediated apoptosis in Hep3B cells. The expression and activity of caspases such as $-3,-8$ and -9 in the WEEH-treated Hep3B cells were examined. The immunoblotting results showed that WEEH treatment down-regulated levels of the inactive pro-caspase-3, -8 and -9 proteins and upregulated levels of active caspase-9. However, bands of active caspase- 3 and -8 were not detected (Fig. 3A). Furthermore, to monitor enzymatic activity during WEEH-induced apoptosis, in vitro caspase activity was measured following treatment with WEEH using specific fluorogenic peptide substrates for each caspase. As shown in Fig. 3B, the activities of these caspases were significantly increased in a concentrationdependent manner. In particular, caspase-3 activity was increased $~ 3.8$ - and 5.2-fold by 0.2 and $0.3 \mathrm{mg} / \mathrm{ml} \mathrm{WEEH}$ treatment, respectively, as compared with untreated control cells (Fig. 4B). These results clearly show that WEEH-induced apoptosis in Hep3B cells is associated with caspase activation. Caspase-3 activation often leads to the proteolytic cleavage of target proteins such as poly-(ADP-ribose) polymerase 
(PARP) (23). Subsequent Western blot analysis showed the progressive proteolytic cleavage of PARP in Hep3B cells after treatment with WEEH. This suggests that caspase- 3 activation is a key step in the WEEH-induced apoptotic pathway in Hep3B cells.

Cleavage of Bid protein and loss of mitochondrial membrane potential by Euphorbiae humifusae treatment. In order to determine whether WEEH-induced apoptosis is associated with mitochondrial dysfunction, we investigated the protein levels of tBid, a BH3-only pro-apoptotic member of the Bcl-2 family. As shown in Fig. 4A, Western blot analyses revealed that treatment with WEEH significantly induced Bid cleavage in a concentration-dependent manner. We also measured MMP levels in WEEH-treated Hep3B cells using the fluorescent cationic dye JC-1. As shown in Fig. 4B, loss of MMP induced by WEEH increased in Hep3B cells, and MMP loss values reached $\sim 20$ and $33 \%$ with 0.2 and $0.3 \mathrm{mg} / \mathrm{ml}$ WEEH treatment, respectively, evidencing the increased depolarization of MMP with increased WEEH treatment. These data indicate that WEEH induced mitochondrial dysfunction, which eventually activated the caspase cascade in the apoptosis signaling of Hep3B cells.

Inhibition of Euphorbiae humifusae-induced apoptosis by caspase-3 inhibitor. To show that caspase-3 activation is a key step in the WEEH-induced apoptotic pathway, the Hep3B cells were pre-treated with z-DEVD-fmk $(50 \mu \mathrm{M})$, a cellpermeable caspase- 3 inhibitor, for $1 \mathrm{~h}$, followed by treatment with $0.3 \mathrm{mg} / \mathrm{ml} \mathrm{WEEH} \mathrm{for} 48 \mathrm{~h}$. Blocking of caspase-3 activity by pre-treatment of the cells with z-DEVD-fmk prevented WEEH-induced PARP degradation and chromatin condensation (Fig. 5A and B). Furthermore, z-DEVD-fmk significantly inhibited not only the increase of annexin $\mathrm{V}$ positive cells, but also the decrease in cell viability caused by WEEH treatment (Fig. 5C and D). These results clearly show that WEEH-induced apoptosis is associated with caspase-3 activation.

\section{Discussion}

Although our recent studies have shown that extracts of E. humifusae suppress the growth of cultured human gastric cancer cells in vitro (19), the signaling pathway by which this occurs has yet to be elucidated. This study aimed to determine the capacity of WEEH to induce apoptosis, and to identify the biochemical mechanisms in a human hepatocarcinoma Hep3B cell line. Our present results demonstrate that WEEH inhibits Hep3B cell growth by inducing apoptotic cell death. Apoptotic induction by WEEH was confirmed by characteristic morphological changes, chromatin condensation, agarose gel electrophoresis and flow cytometry (Fig. 1).

Apoptosis is an endogenous programmed cell death that can be triggered by various stimuli, including death receptormediated signaling (via the death receptor/extrinsic pathway) and intracellular stress (via the mitochondrial/intrinsic pathway). It is widely accepted that alterations in mitochondrial structure and function, as well as in caspase activation, play important roles in apoptosis, and are involved in a variety of key events leading to apoptosis (4-6). To gain insight into the mechanism of the WEEH-induced apoptosis of Hep3B cells, the catalytic activity of caspases and mitochondrial dysfunction were investigated. The present data demonstrate that WEEH increased the enzymatic activity of extrinsic and intrinsic caspase cascades, such as caspase-8 and -9. Cell surface Fas/ FasL and TRAIL/DRs systems are key signaling transduction pathways of the extrinsic pathway of apoptosis in cells. Binding FasL to Fas receptors and TRAIL to DRs leads to receptor oligomerization and the formation of the deathinducing signaling complex, followed by caspase- 8 activation and Bid cleavage $(7,8)$. Our results, which show increased levels of death receptor-related proteins such as Fas, TRAIL, DR4 and DR5, caspase-8 activation, and increased tBid expression in Hep3B cells treated with WEEH (Fig. 4), suggest that a change in the extrinsic pathway may contribute to WEEH-induced apoptosis of Hep3B cells.

Mitochondria are known as important regulators of extrinsic as well as intrinsic apoptotic pathways, and undergo a series of consequential changes during apoptosis. The loss of MMP, together with the permeability transition of membrane pores, is an early event in the apoptotic cascades resulting in mitochondrial swelling and disruptions of the outer mitochondrial membrane. Mitochondrial function is controlled by several factors, such as the pro- and anti-apoptotic members of the Bcl-2 family (5-8). tBid can translocate to mitochondria and bind to Bax, leading to a conformational change of proapoptotic Bax and caspase-9 activation. In the present study, WEEH resulted in mitochondrial dysfunction evidenced by the loss of MMP, as observed by JC-1 staining and caspase- 9 activation (Figs. 3 and 4). Furthermore, WEEH was found to increase Bax levels and decrease those of anti-apoptotic Bcl-2 and Bcl-xL. These changes may have increased mitochondrial depolarization and led to caspase- 9 activation, which indicates that $\mathrm{WEEH}$ increased the $\mathrm{Bax} / \mathrm{Bcl}-2$ or $\mathrm{Bax} / \mathrm{Bcl}-\mathrm{xL}$ ratio and induced mitochondrial dysfunction, resulting in apoptosis in Hep3B cells.

The activation of the mitochondrial pathway leads to the release of Smac/Diablo, which removes the IAP blockage of caspase activation (5-8). The IAP family functions by binding to and inhibiting several caspases $(24,25)$. Caspase signaling is initiated and propagated by proteolytic autocatalysis, and by the cleavage of downstream caspases and substrates $(26,27)$. In addition, caspase- 3 is known to be one of the key executioners of apoptosis, since it is either partially or totally responsible for the proteolytic cleavage of many key proteins. These include PARP, which is important for cell viability, but also serves as a marker of apoptosis when cleaved (23). Further studies have shown that exposure of Hep3B cells to WEEH causes a downregulation of IAP family proteins such as XIAP, cIAP-1 and cIAP-2, caspase-3 activation and the concomitant degradation of PARP (Figs. 2 and 3). The present results indicate that WEEH increases mitochondrial dysfunction, which, in turn, results in caspase- 9 activation, leading to caspase- 3 activation, which is also associated with the inhibition of IAP family protein functions. Specifically, we found that treatment with WEEH in the presence of the caspase-3 inhibitor prevented apoptosis and growth inhibition by blocking the proteolytic activation of caspase-3, PARP cleavage, DNA fragmentation and apoptotic body formation induced by WEEH (Fig. 5). These data suggest that WEEH-induced apoptosis was caused 
by caspase-3-dependent cell death, and that caspase- 3 plays an important role in WEEH-induced apoptosis in Hep3B cells.

In summary, the results of this study demonstrate that WEEH triggers the apoptosis of Hep3B cells through the activation of the intrinsic caspase pathway along with the death receptor-mediated extrinsic pathway. Although further studies are needed to examine the mechanisms in detail, these results provide further information on the possible mechanisms of the anti-cancer activity of extracts of E. humifusae.

\section{References}

1. Okada $\mathrm{H}$ and Mak TW: Pathways of apoptotic and nonapoptotic death in tumour cells. Nat Rev Cancer 4: 592-603, 2004.

2. Jin Z and El-Deiry WS: Overview of cell death signaling pathways. Cancer Biol Ther 4: 139-163, 2005.

3. Han SI, Kim YS and Kim TH: Role of apoptotic and necrotic cell death under physiologic conditions. BMB Rep 41: 1-10, 2008.

4. Ghobrial IM, Witzig TE and Adjei AA: Targeting apoptosis pathways in cancer therapy. CA Cancer J Clin 55: 178-194, 2005.

5. Jeong SY and Seol DW: The role of mitochondria in apoptosis BMB Rep 41: 11-22, 2008.

6. Wesche-Soldato DE, Swan RZ, Chung CS and Ayala A: The apoptotic pathway as a therapeutic target in sepsis. Curr Drug Targets 8: 493-500, 2007.

7. Galluzzi L, Larochette N, Zamzami N and Kroemer G: Mitochondria as therapeutic targets for cancer chemotherapy. Oncogene 25: 4812-4830, 2006.

8. Javadov S and Karmazyn M: Mitochondrial permeability transition pore opening as an endpoint to initiate cell death and as a putative target for cardioprotection. Cell Physiol Biochem 20: 1-22, 2007.

9. Huang CF, Lin SS, Liao PH, Young SC and Yang CC: The immunopharmaceutical effects and mechanisms of herb medicine. Cell Mol Immunol 5: 23-31, 2008.

10. Ruan WJ, Lai MD and Zhou JG: Anticancer effects of Chinese herbal medicine, science or myth? J Zhejiang Univ Sci B 7: 1006-1014, 2006.

11. Kummalue T: Molecular mechanism of herbs in human lung cancer cells. J Med Assoc Thai 88: 1725-1734, 2005.

12. Cohen I, Tagliaferri $M$ and Tripathy D: Traditional Chinese medicine in the treatment of breast cancer. Semin Oncol 29: 563-574, 2002.

13. Zhuang LX, Zhao MH, Yang JJ and Deng QP: A study on the time-effect relationship in the treatment of bronchial asthma with medicinal vesiculation therapy. Zhen Ci Yan Jiu 32: 53-57, 2007.
14. Xia L, Bai LP, Chu C, Li P, Jiang ZH and Zhao ZZ: Authentication of the 31 species of toxic and potent Chinese materia medica (T/PCMM) by microscopic technique, part 2: Three species of seed T/PCMM. Microsc Res Tech 71: 325-333, 2008.

15. Xing JB, Shui CH and Liu Y: Determination of quercetin in the Herba Euphorbiae humifusae. Zhongguo Zhong Yao Za Zhi 27: 758-760, 2002.

16. Li ZG, Sun XG, Zhou KF, Lei LC and Zhai YJ: Determination of esculetin in semen Euphorbiae lathyridis L. by TLCS and comparison on the quality in different areas. Zhongguo Zhong Yao Za Zhi 18: 458-459, 1993.

17. Kim TH, Jin CY, Park SE, Kim WI, Park DI, Kim GY, Kim ND, Hong SH and Choi YH: Euphorbiae humifusae inhibits Egr-1, $\mathrm{NF}-\kappa \mathrm{B}$ and $\mathrm{COX}-2$ activity stimulated by phorbol 12-myristate13-acetate. Kor J Oriental Physiol Pathol 22: 415-421, 2008.

18. Seo SH, Shin DY, Hong SH, Park SE, Kim WI, Park DI, Choi YH and Hong SH: Growth inhibition of human hepatocarcinoma cells by water extract of Euphorbiae humifusae was associated with the inhibition of prostaglandin $\mathrm{E}_{2}$ and $\mathrm{NO}$ synthesis. Cancer Prev Res 13: 130-136, 2008.

19. Lee JJ, Shin DH, Park SE, Kim WI, Park DI, Choi YH and Hong SH: Euphorbiae humifusae sensitizes apoptosis of TRAILresistant human gastric adenocarcinoma AGS cells. J Life Sci 18: 120-128, 2008.

20. Dash R, Acharya C, Bindu PC and Kundu SC: Antioxidant potential of silk protein sericin against hydrogen peroxide-induced oxidative stress in skin fibroblasts. BMB Rep 41: 236-241, 2008.

21. Lee KB, Lee JS, Park JW, Huh TL and Lee YM: Low energy proton beam induces tumor cell apoptosis through reactive oxygen species and activation of caspases. Exp Mol Med 40: 118-1129, 2008.

22. Lee W, Choi HI, Kim MJ and Park SY: Depletion of mitochondrial DNA up-regulates the expression of MDR1 gene via an increase in mRNA stability. Exp Mol Med 40: 109-117, 2008.

23. Lazebnik YA, Kaufmann SH, Desnoyers S, Poirier GG and Earnshaw WC: Cleavage of poly(ADP-ribose) polymerase by a proteinase with properties like ICE. Nature 371: 346-347, 1994.

24. Hunter AM, LaCasse EC and Korneluk RG: The inhibitors of apoptosis (IAPs) as cancer targets. Apoptosis 12: 1543-1568, 2007.

25. Eckelman BP, Salvesen GS and Scott FL: Human inhibitor of apoptosis proteins: why XIAP is the black sheep of the family. EMBO Rep 7: 988-994, 2006.

26. Hengartner MO: The biochemistry of apoptosis. Nature 407: 770-776, 2000.

27. Suda T, Takahashi T, Golstein P and Nagata S: Molecular cloning and expression of the Fas ligand, a novel member of the tumor necrosis factor family. Cell 75: 1169-1178, 1993. 